\title{
A Follow up Study: New Nurse Graduates’ Performance Evaluation in a Familiarized Nursing Environment when "Everything is New to Everyone"
}

\section{Hamidah $\mathbf{H}$ and Annamma $\mathbf{K}^{*}$}

School of Nursing, KPJ Healthcare University College, Lot PT 17010, Persiaran Seriemas, Kota Seriemas, Nilai, Negeri Sembilan Darul Khusus, Malaysia

"Corresponding author: Annamma Kunjukunju, School of Nursing, KPJ Healthcare University College, Lot PT 17010, Persiaran Seriemas, Kota Seriemas, Nilai, Negeri Sembilan Darul Khusus, Malaysia, Tel: 606-7942131/2632; Fax:606-7942662; E-mail: ann@kpjuc.edu.my

Received date: May 01, 2018; Accepted date: Jun 21, 2018; Published date: Jun 26, 2018

Copyright: ( 2018 Hamidah $\mathrm{H}$, et al. This is an open-access article distributed under the terms of the Creative Commons Attribution License, which permits unrestricted use, distribution, and reproduction in any medium, provided the original author and source are credited.

\begin{abstract}
Performance evaluation is a continuous process in assessing the employee's contribution to the organization. The aim of performance evaluation is to achieve an equitable capacity of the employee's contribution to the workplace. In nursing, the evaluation performance encompasses cognitive skills; affective and psychomotor domains. The aim of this study was to evaluate the new nurse graduates' performance who had been trained within an environment of 'everything is new to everyone' in one of the teaching hospitals. A comparative descriptive study was conducted with 113 staff nurses as after 2 years of graduation. Work performance domains evaluated are; punctuality, physical appearance, attitude and commitment to work, service excellence, positive relationship, communication skills, and leadership. Results had shown $76.02 \%$ of the new nurse graduates' performance was excellent as evaluated by the $1^{\text {st }}$ evaluators. Similar results were obtained from the overall evaluation of the $2^{\text {nd }}$ evaluators. However, in some aspect of the overall evaluations, there was an inconsistency that contradicts the evaluation of both evaluators. A system will run accordingly if it is well communicated and had mutual consensus between evaluators who regard performance evaluation is rather a continuous process even in a difficult environment when everything is new to everyone.
\end{abstract}

Keywords: Performance evaluation; Performance evaluators; Nursing

\section{Introduction}

Performance evaluations are a constructive process to acknowledge the performance of a non-probationary career employee. It provides employers an opportunity to assess their employees' contributions to the organization and it is essential for the development teamwork strategies

The main goals of a performance evaluation system are to provide an equitable measurement of an employee's contribution to the workforce $[1,2]$.

A well-designed departmental performance evaluation system will allow a department to justify its functions and demonstrate the quality of care by providing concrete measures of performance, positive feedback on the well-done job, which motivates personal growth [3]. Performance evaluation requires integration of standards and competencies that recognize the achievement and milestones in an employee's professional growth [4].

In Nursing, clinical performance encompasses more than just cognitive skills. It also includes the levels of cumulative of affective and psychomotor domains, such as interests, attitudes, opinions, appreciations, values, and emotional sets and reflects a change in attitude or behaviour [5]. The assessment of performance should practice more than one indicator, regardless of the tool or indicator; it is essential that there is the adequate preparation of the individual being assessed [6]. It was suggested that the assessors or mentors should collaborate with the on-going process plan of performance evaluation on the employee's work. However, to some managers' performance appraisal were developed as a general appraisal, which caused injustice to the staff being assessed [7].

Performance appraisal should consist of personal attributes such as job, knowledge, quality and quantity of work, teamwork, attendance, safety, problem solving, cost control and communications $[8,9]$.

\section{Background}

This study was conducted on the first batch of 113 new nurse graduates who were trained in one of teaching hospitals in Kuala Lumpur. Those new graduates underwent 3 years Diploma of Nursing Program where the environment of the school and the hospital where everything was new.

The new hospital employed 850 registered nurses from at least twelve institutions within the country and some were from the neighbouring countries and they were employed to assist in the management of patient care and management of the Nursing Service Department. Seven local nurse managers and 33 head nurses were employed to manage the nursing administration. A lot of efforts were put on maintaining optimum nursing input in the face of an acute shortage of staff of this hospital as the nursing staff from the neighbouring would leave the hospital after two years of service.

The above situation resulted in problems related to the delivery of patient care like duties carried out as a matter of routine. Patient's length of stay, compliance to treatment or early rehabilitation, for instance, were hardly ever on concerns. Indeed, that was the environment within which those new nurse graduates were being prepared and their performance as staff nurses or charge nurses is 
Page 2 of 5

being evaluated. During their training, those new nurse graduate nurses received close supervision by the 15 new nurse educators throughout the training, with a teacher student ratio of 1:9. The training institution believed that the first two years of training were the most critical time to develop the student's competencies to be a nurse. A model of patient care called, A patient care system was created and adapted specifically when students were in the clinical posting. The clinical setting is the most influential environment in the development of nursing skills, knowledge and professional socialization [10]. In the final year of their training, those new nurse graduates were placed in the special care areas. That was the year when those graduates would decide for their area of interest to be a staff nurse or charge nurse. Upon graduation they were given their preferred choice of specialty. Two years after the graduation, feedbacks were received on the new nurse graduates' performance. They were monitored by the head nurses using a checklist which was similar to the checklist in the patient care system. The head nurses were the front line managers who were all the time in contact with the new nurse graduates. The nurse managers as the second evaluators were seldom in contact with these new nurse graduates, as their main position, needs them to cover more areas within their own discipline. There is no single procedure for adequate assessment technique for assessing the staff's performance [11]. The main measurement used is either by direct observation or through verbal communication. Hence, the validity and reliability of the methods used are always questionable.

\section{Methods}

\section{Study design}

This study is comparative descriptive study, which compared the performance evaluation of new graduates done by the head nurse as a first evaluator and the nurse managers as the second evaluator.

\section{Sample size and sampling}

The total population of the study which was 113 new graduates as sample of the study. A convenient sampling technique used and they were actually graduated nurses from the first batches of the Diploma of Nursing Program, Medical Faculty of Universiti Kebangsaan Malaysia, working in the new tertiary hospital. They have been placed in all the 33 newly opened wards to provide patients care.

\section{Data collection method}

Part one: Sets of the questionnaire were given to all head nurses, to evaluate the performance of the new nurse graduates on the six aspects of work performance based on Performance Measurement (Table 1) [12].

Likert Scale was used to score the performance evaluation; $0=I$ don't know, 1=never, $2=$ seldom, 3=sometimes, $4=$ always. Each question scored from 0 to 4 points. The highest score will be 24 points. The higher the score the more positive would be the success of the respondent's performance.

Part two: Evaluation of the new nurse graduates' performance by the nurse managers as the second evaluator. Three sets of open-ended questionnaires used as the guideline interview.

Question 1: "How do you find their performance in the ward as a staff nurse or charge nurse?"
Question 2: "Would you identify 3 three of good things about these new nurse graduates and three areas where improvement could be seen?"

Question 3: "How would you believe that could be adjusted?"

\begin{tabular}{|l|l|l|}
\hline Domains & $\begin{array}{l}\text { Number } \\
\text { Questions }\end{array}$ & $\begin{array}{l}\text { Total } \\
\text { Scoring }\end{array}$ \\
\hline Punctuality & 3 & 12 \\
\hline Physical appearance & 3 & 12 \\
\hline Attitude and commitment to work & 6 & 24 \\
\hline Service excellence & 10 & 40 \\
\hline $\begin{array}{l}\text { Positive relationship and Communication } \\
\text { skills }\end{array}$ & 5 & 20 \\
\hline Leadership & 6 & 24 \\
\hline
\end{tabular}

Table 1: Six domains of work performance and scoring.

\section{Ethical consideration}

Approval to conduct the study obtained from the Research Committee of the Teaching Hospital.

\section{Analysis}

Statistical Package for Social Science (SPSS) version 12.0 and descriptive analysis were used to analyse the data.

\section{Results}

\begin{tabular}{|l|l|l|l|}
\hline & Domains & $\begin{array}{l}\text { Average } \\
\text { Score }\end{array}$ & STDEV \\
\hline 1 & Punctuality & 3.3 & 0.4864 \\
\hline 2 & Physical appearance & 3.6 & 0.464 \\
\hline 3 & Attitude Towards work & 3.23 & 0.5085 \\
\hline 4 & Service Excellence & 3.36 & 0.535 \\
\hline 5 & Relationship and communication & 3.09 & 0.5464 \\
\hline
\end{tabular}

Table 2: The average score, and the standard deviation of work performance of the new nurse graduates.

Table 2 showed the average score, and the standard deviation of each domain scored by the head nurses. The highest average score was 3.6 on service excellence, followed by physical appearance $($ mean $=3.36)$, punctuality $($ mean $=3.30)$, attitude towards work $($ mean $=3.23)$, and the lowest average scores were relationship and communication, and leadership, both received mean $=3.09$.

The overall achievement of the work performance scored in percentage, compare with the CGPA achieved as shown in Table 3. A total of $86(76.10 \%)$ new nurse graduates had achieved Excellent performance, and 20 (17.69\%) had achieved Very Good, 3 (2.64\%) achieved Satisfactory and 4 (3.52\%) scored Pass.

\begin{tabular}{|l|l|l|l|l|}
\hline $\begin{array}{l}\text { Clinical } \\
\text { Performance }\end{array}$ & $\mathrm{N}=113$ & CGPA $>3.00$ & CGPA $<3.00$ & Total \\
\hline
\end{tabular}


Citation: Hamidah H, Annamma K (2018) A Follow up Study: New Nurse Graduates' Performance Evaluation in a Familiarized Nursing Environment when "Everything is New to Everyone". J Nurs Care 7: 458. doi:10.4172/2167-1168.1000456

Page 3 of 5

\begin{tabular}{|l|l|l|l|l|}
\hline Excellence Score & 86 & $69(61.06 \%)$ & $17(15.04 \%)$ & $76.10 \%$ \\
\hline Very Good & 20 & $13(11.50 \%)$ & $7(6.19 \%)$ & $17.69 \%$ \\
\hline Satisfactory & 3 & $2(1.76 \%)$ & $1(0.88 \%)$ & $2.64 \%$ \\
\hline Pass & 4 & $2(1.76 \%)$ & $2(1.76 \%)$ & $3.52 \%$ \\
\hline TOTAL & 113 & $86(76.02 \%)$ & $27(23.87 \%)$ & $100 \%$ \\
\hline
\end{tabular}

The highest Work Performance scored by the 113 new nurse graduates was on the Service Excellence with the average score of 3.36., as shown in Table 4, through the following items.

The performance evaluation made by the $2^{\text {nd }}$ evaluator in surgical units contradicted as shown in Table 5, with the evaluation made by the $1^{\text {st }}$ evaluators of the same units. Their performance evaluation had shown that $20(86.95 \%)$ of 23 new nurse graduates had performed well, but only three had performed 'good' as shown in Table 6. However, the evaluation made by the $2^{\text {nd }}$ evaluator had affected the 23 new nurse

Table 3: The overall scoring of work performance by the first evaluators against Cumulative Grade Point Average (CGPA). graduates' performance.

\begin{tabular}{|c|c|c|c|c|c|}
\hline Service Excellence & Always & Sometimes & Seldom & Never & I don't know \\
\hline Maintain clean, organized, safe patient care & $59(52.2 \%)$ & $46(40.70 \%)$ & $7(6.2 \%)$ & $1(0.90 \%)$ & - \\
\hline $\begin{array}{l}\text { Communicate appropriately every time When } \\
\text { sees patients }\end{array}$ & $61(54.0 \%)$ & $44(38.90 \%)$ & $8(7.1 \%)$ & - & \\
\hline Touch her patients when providing care & $70(61.9 \%)$ & $37(32.70 \%)$ & $6(5.3 \%)$ & - & \\
\hline Smile at patients & $62(54.9 \%)$ & $45(39.8 \%)$ & $5(4.4 \%)$ & $1(0.90 \%)$ & \\
\hline Responds promptly when called by patient. & $64(56.6 \%)$ & $42(37 \%)$ & $6(5.30 \%)$ & $1(0.90 \%)$ & \\
\hline Pretend to be busy & $3(2.70 \%)$ & $15(13.30 \%)$ & $44(38.90 \%)$ & $44(38.90 \%)$ & \\
\hline Practice patient safety strategies & $72(63.7 \%)$ & $41(36.3 \%)$ & - & - & \\
\hline $\begin{array}{l}\text { Recognized patients' physiological and } \\
\text { psychological needs }\end{array}$ & $33(29.2 \%)$ & $70(61.9 \%)$ & $8(7.1 \%)$ & $1(0.9 \%)$ & $1(0.90 \%)$ \\
\hline Act promptly according to the patient's needs. & $54(47.8 \%)$ & $52(46.0 \%)$ & $6(5.3 \%)$ & $1(0.9 \%)$ & \\
\hline Follow physician's orders correctly. & $78(69 \%)$ & $31(27.40 \%)$ & $3(2.70 \%)$ & $1(0.90 \%)$ & \\
\hline
\end{tabular}

Table 4: Highest work performance’s domain-service excellence.

\begin{tabular}{|c|c|c|}
\hline Units & $\begin{array}{l}\text { Number of new nurse } \\
\text { graduate }\end{array}$ & Statement made by the $2^{\text {nd }}$ Evaluator \\
\hline $\begin{array}{l}\text { General OT, CSSD, Infection Control } \\
\text { Unit }\end{array}$ & 8 & Overall performance is good, good attitude, good knowledge, and skills. \\
\hline Ambulatory Services & 1 & Poor knowledge, poor attitude, poor in skills and poor communication. \\
\hline Medical Units & 23 & More than $75 \%$ of the graduates had a good attitude, good knowledge, and skills. \\
\hline $\begin{array}{l}\text { Pediatrics, Oncology, Psychiatry, Special } \\
\text { units }\end{array}$ & 12 & More than $75 \%$ of the graduates had a good attitude, good knowledge, and skills. \\
\hline Surgery units & 23 & $\begin{array}{l}\text { Only one graduate is 'good.' The rest were poor knowledge, poor in skills, poor attitude } \\
\text { and poor in communication. }\end{array}$ \\
\hline Obstetrics and Gynecology & 10 & Good attitude, poor in skills and poor knowledge. \\
\hline Emergency Medicine & 10 & Good knowledge, better skills, and good attitude. \\
\hline $\mathrm{NICU}$ & 13 & More than $75 \%$ of the graduates had a good attitude, good knowledge and skills. \\
\hline ICU, CCU, CRW & 13 & Most graduates had a good attitude, good knowledge, and skills. \\
\hline
\end{tabular}

Table 5: Responses from $2^{\text {nd }}$ Evaluators: "How do you find the performance of the new nurse graduates in your units?".

\section{Discussion}

The majority of the new nurse graduates, 86 (76.1\%) had achieved excellent performance rated by the respective head nurses, 20 (17.69\%) of them received 'very good' performance. If these two groups were to group together, the result would show as 106 (93.8\%) of new nurse graduates out of 113 had performed very well as staff nurses or charge nurses after two years of graduation. The result had also confirmed with the Cumulative Grade Point Average (CGPA), 82 (72.56\%) of 113 
Page 4 of 5

graduates who obtained CGPA of 3 and above, performed very well as a staff nurse and those graduates who received CGPA less than 3 during their training $24(21.23 \%)$ also performed well after two years of graduation particularly the new nurse graduates who worked in special areas.

There could be many factors that contributed to the excellent performance among the new nurse graduates. One of the factors could be the training and working in the same place $[13,14]$. Those new nurse graduates received close supervision from the [15] new nurse educators throughout the 3 year program. Being the first batch, they were given special attention and everything was made new for them, A model of patient care called, A Patient care System was created specifically for them to manage in the patient care.

Understanding the new graduate nurses' experiences and their unmet needs during their first year of practice will enable nurse managers, educators and nurses to better support new graduate nurses' and promote confidence and competence to practice within their scope [16].

In the final year of the training, those new nurse graduates were given the freedom to choose the ward where they like to work after graduated. These factors could be the reason why more than $80 \%$ of the new nurse graduates functioned well over two years working at the hospital where they were trained. The job satisfaction and career retention of new nurses are related to perceptions of work environment factors that support their professional practice behaviours and highquality patient care [17]. The majority of the new nurse graduates functioned well in areas such as operating theatre, emergency medicine and Neonatal Intensive Care Unit. They were consistently ranked high working in those areas.

\begin{tabular}{|l|l|l|}
\hline $\begin{array}{l}\text { Number of new nurse } \\
\text { graduates in Surgery } \\
\text { units }\end{array}$ & $\begin{array}{l}\text { Total Performance } \\
\text { Score (24 points) }\end{array}$ & Grading Performance \\
\hline & \multicolumn{2}{|l|}{ Performance Evaluation by ${ }^{\text {st }}$ Evaluators (\%) } \\
\hline 1. & 2287.00 & Excellent \\
\hline 2. & 22.87 & Excellent \\
\hline 3. & 22.73 & Excellent \\
\hline 4. & 2253.00 & Excellent \\
\hline 5. & 22.37 & Excellent \\
\hline 6. & 2220.00 & Excellent \\
\hline 7. & 21.96 & Excellent \\
\hline 8. & 2193.00 & Excellent \\
\hline 9. & 21.6 & Excellent \\
\hline 10. & 2160.00 & Excellent \\
\hline 11. & 21.1 & Excellent \\
\hline 12. & 2090.00 & Very good \\
\hline 13. & 20.47 & Very good \\
\hline 14. & 2030.00 & Very good \\
\hline 15. & 20.3 & Very good \\
\hline
\end{tabular}

\begin{tabular}{|l|l|l|}
\hline 16. & 20.13 & Very good \\
\hline 17. & 19.63 & Very good \\
\hline 18. & 19.5 & Very good \\
\hline 19. & 17.84 & Very good \\
\hline 20. & 17.36 & Very good \\
\hline 21. & 14.34 & Good \\
\hline 22. & 13.97 & Good \\
\hline 23. & 13.9 & Good \\
\hline
\end{tabular}

Table 6: Performance evaluation by $1^{\text {st }}$ Evaluators in Surgical units.

However, for the 23 new nurse graduates who worked in the surgical units, received a pessimistic statement by the $2^{\text {nd }}$ evaluator as; "only one could function well while the rest were poor in knowledge, poor in skills, poor in attitudes, and poor in communication." That statement contradicted with the assessment made by the $1^{\text {st }}$ evaluators in all the surgical units. Their performance evaluation rated as $20(86.95 \%)$ out of 23 graduates had performed well and three had performed 'good.' This single and isolated assessment made by the particular assessor resulted in the inconsistency between the first and the second evaluator of the same unit. The decision made could be caused by a feeling of incoherent. The limitations of performance appraisal and staff development, however, occur when management and staff do not understand the principles of performance appraisal and the need for consultation with staff about staff development activity [15]. Some managers tend to be liberal or strict in rating staff, some may fall into the trap of "recent performance effect." They generally will recall only recent favourable or unfavourable events rather than the whole years' worth activities [14]. On the other hand $2^{\text {nd }}$ evaluator in the medical units said more than $75 \%$ of the new nurse graduates can function well referring to Table 5. The number of new nurse graduates in surgical units and medical units was distributed equally, 23 new nurse graduates to each discipline. It was not a possible mistake in giving the final say about the graduates' performance as only one was 'good'.

\section{Conclusion}

In a new place, where the environment is "everything is new to everyone," the system will take time for it to work well. What's important are the approaches to make the system works, one approach will not be sufficient enough? In evaluating the staff performance, an observation only is not sufficient to decide the final say that someone is good or not good. Some managers tend to fall into the trap of "recent performance effect."

\section{References}

1. Cruz S (1997) Evaluating academic performance of under graduates policy and guidelines.

2. Capko J (2003) 5 steps to a Performance Evaluation System. Fam Prac Manag 10: 43-48.

3. Roberts GE (2002) Employee performance appraisal system participation: A technique that works. PPM 32: 89-98.

4. Smith KN, Kathleen N, Gunzenhauser DJ (2010) Reinvigorating performance evaluation: first steps in a local health department. Public Health Nurs 27: 425-32. 
Citation: Hamidah H, Annamma K (2018) A Follow up Study: New Nurse Graduates' Performance Evaluation in a Familiarized Nursing Environment when "Everything is New to Everyone". J Nurs Care 7: 458. doi:10.4172/2167-1168.1000456

Page 5 of 5

5. Evans A (2008) Competency assessment in nursing: A summary of literature published since 2000.

6. Sherman R, Pross E (2010) Growing future nurse leaders to build and sustain healthy work environments at the unit level. OJIN 15: 10-22.

7. Swansburge RC (1996) Management and Leadership for Nurse Managers. Jones and Bartlett Publisher, Canada.

8. Roberts MB, Keith MR (2003) Implementing a performance evaluation system in a correctional managed care pharmacy. Am J Health Syst Pharm 59: 80-89.

9. Evans J, Boxer E, Sanber S (2005) The strengths and weaknesses of transitional support programs for newly registered nurses. AJAN 25: 16-22.

10. Edward H, Smith S, Courtney M, Finlayson K, Chapman H, et al. (2004) Impact of clinical placement location of nursing students competence and preparedness for practice Nurse Educ Today 24: 248-255.

11. Shaw JB (2006) Evaluating employee performance: Tips and pitfalls.
12. Jaschik S (2015) Well prepared in their own eye. The university of Arkansas. Washington, USA.

13. McKane CL (2004) Clinical objectives: A method to evaluate clinical performance in critical care orientation. J Nurses Staff Dev 20: 134-139.

14. Metcalf C (2008) The importance of performance appraisal and staff development: A graduating Nurse's perspectives. Int J Nurs Pract 7: 54-56.

15. Chaponda NC (2014) The effect of performance Appraisal on employee motivation: a survey of slum-based non governmental organization in Nairobi. United State International University of South Africa.

16. Rafic H, Everett B, Ramjan LM, Hu W, Salamonson Y (2017) New graduate nurses'experience in a clinical specialty: A follow up study of newcomers perceptions of transitional support. BMC Nursing 16: 42-44.

17. Spence LHK, Zhu J, Read E (2016) Nurses perception of professional practice behaviour, quality of care, job satisfaction and career retention. J Nurs Manag 24: 656-665. 